\title{
A History of Cow's Milk Allergy Is Associated with Lower Vitamin D Status in Schoolchildren
}

\section{Rosendahl, Jenni}

2017

Rosendahl , J , Fogelholm , M , Pelkonen , A , Makela , M J , Makitie , O \& Erkkola , M 2017

, ' A History of Cow's Milk Allergy Is Associated with Lower Vitamin D Status in

Schoolchildren ' , Hormone research in paediatrics , vol. 88 , no. 3-4 , pp. 244-250 . https://doi.org/10.1159/0004787

http://hdl.handle.net/10138/237147

https://doi.org/10.1159/000478779

cc_by_nc_nd

acceptedVersion

Downloaded from Helda, University of Helsinki institutional repository.

This is an electronic reprint of the original article.

This reprint may differ from the original in pagination and typographic detail.

Please cite the original version. 
History of cow's milk allergy is associated with lower vitamin D status in schoolchildren

Jenni Rosendahl ${ }^{1}$, Mikael Fogelholm², Anna Pelkonen ${ }^{3}$, Mika J. Mäkelä $^{3}$, Outi Mäkitie ${ }^{1}$, Maijaliisa Erkkola²

${ }^{1}$ Children's Hospital, University of Helsinki and Helsinki University Hospital, Helsinki, Finland

2Division of Nutrition, Department of Food and Environmental Sciences, University of Helsinki, Helsinki, Finland

${ }^{3}$ Department of Allergy, University of Helsinki and Helsinki University Hospital, Helsinki, Finland

Short title: Milk allergy and vitamin D status

Key words: children; cow's milk allergy; supplementation; vitamin D; vitamin D fortification

Corresponding author: Jenni Rosendahl, mailing address Tukholmankatu 8 C, P.O. Box 20

Biomedicum, Helsinki, 00014 University of Helsinki; e-mail address jenni.rosendahl@helsinki.fi; phone +358505980512 


\begin{abstract}
Background/Aims

Vitamin D insufficiency is common in children. We aimed to evaluate the main determinants of vitamin D status in Finnish school-aged children, including history of allergic disease.
\end{abstract}

Methods

We conducted a cross-sectional study on 171 10-year-olds where serum 25-hydroxyvitamin D $(25(\mathrm{OH}) \mathrm{D})$ levels were measured, and data on food consumption and use of vitamin $D$ supplements were collected. The history of allergic diseases was evaluated with a validated questionnaire.

\title{
Results
}

Vitamin D insufficiency ( $<50 \mathrm{nmol} / \mathrm{L}$ ) was observed in $16 \%$ of the children. In children with a history of cow's milk allergy, the mean $25(\mathrm{OH}) \mathrm{D}$ levels were lower than in children without allergy $(60.5 \pm 12.6 \mathrm{nmol} / \mathrm{L}$ vs. $75.5 \pm 22.3 \mathrm{nmol} / \mathrm{L}, \mathrm{p}=0.004)$. Lack of vitamin $\mathrm{D}$ supplementation, female gender, non-Caucasian ethnicity and a history of milk allergy were associated with lower vitamin $D$ status.

\section{Conclusion}

The vitamin D status in our study sample of Finnish schoolchildren was sufficient which suggests that health policy strategies such as recommendation of vitamin D supplementation and fortification of food products with vitamin D have been successful in improving vitamin D status in children. Special concern should be given to children with a history of milk allergy to ensure their vitamin D sufficiency. 


\section{Introduction}

Vitamin D modulates bone health and growth, and has several extra-skeletal effects, including regulation of immune functions [1]. In epidemiological studies vitamin D status has been associated with allergy and asthma, and with other immune-mediated diseases such as type 1 diabetes and multiple sclerosis [2-4].

Vitamin D deficiency is a major health concern in many countries, especially in the northern latitudes where exposure to sunlight is limited [5]. In Finland, liquid milk products and fat spreads have been fortified with vitamin D since 2003. In 2010, the fortification of liquid milk products and fat spreads was doubled, the recommended vitamin D fortification being presently $1 \mu \mathrm{g}$ (40 IU) per $100 \mathrm{ml}$ for milk products and $20 \mu \mathrm{g}(800 \mathrm{IU})$ per $100 \mathrm{~g}$ for spreads. Finland also has a national recommendation for year-round vitamin D supplementation, which since 2011 includes all children from age 2 weeks to 18 years. Currently all children aged 2 weeks to 2 years are recommended to take a daily supplement of $10 \mu \mathrm{g}$ (400 IU), and 2- to 18-year-old children a daily supplement of $7.5 \mu \mathrm{g}$ (300 IU) of vitamin D3 [6].

Allergic diseases are among the most common chronic diseases in children in the developed countries [7]. The lifetime self-reported prevalence of allergy to common foods in Europe ranges from $0.6-6 \%$ [8]. Food allergy may lead to extensive elimination diets that may affect nutrient intake and growth of children [9].

The aim of this study was to evaluate the overall vitamin D status in Finnish 10-year-old schoolchildren after the changes in the national policy of food fortification and vitamin $D$ supplementation, and to examine the main determinants of vitamin D status and the role of allergic diseases therein.

\section{Materials and methods}

\section{Study subjects}

The ISCOLE study (International Study on Childhood Obesity, Lifestyle and the Environment) is a multi-national cross-sectional study conducted in 12 countries aiming to determine the relationships between lifestyle behaviors and obesity [10]. ISCOLE's sample included children from semi-urban and urban areas, and they were recruited from schools stratified by indicators of socio-economic status. In the present study we used data collected in the allergy sub study in Finland. Altogether 542 10-year-old 4th grade students from 13 primary schools in the capital region of Finland were recruited to the study. Vitamin D status was measured for 171 participants and for 160 of them the history of allergic diseases was evaluated, as presented in the recruitment flow chart (Fig. 1). The main characteristics (sex, ethnicity, BMI, use of vitamin D supplement and history of cow's milk allergy) of the 171 children did not differ from the ISCOLE cohort. This study was conducted according to the Declaration of Helsinki and all procedures were approved by the 
Helsinki and Uusimaa Hospital District Ethics Committees. Children provided their assent to participate in the study, and parents or legal guardians provided informed consent.

\section{Data collection}

The participants' parents were invited to complete a questionnaire on basic demographics, ethnicity, family health, socioeconomic factors and use of vitamin D supplements. Data on food consumption was obtained from the participating children and included a validated food frequency questionnaire comprising 23 food and beverage groups [11]. The consumption of milk products and fish was inquired with 7 frequency alternatives: never; less than once a week; once a week; 2-4 days a week; 5-6 days a week; once a day, every day; and every day, more than once per day. The vitamin $D$ content of the foods was calculated using the Finnish Food Composition Database (Fineli, version 2013, National institute for Health and Welfare). Use of vitamin D supplements was inquired with 4 frequency alternatives: never; once a week or less; 2-5 days a week; and daily or almost daily. Time spent outdoors was reported in hours per day before and after school or on the weekend (less than 1 hour, 1 hour, 2 hours, 3 hours, 4 hours or more than 5 hours).

Information on allergic symptoms and diagnosis of allergic diseases was obtained from a modified International Study of Asthma and Allergies in Childhood (ISAAC) based questionnaire [12]. The parents were asked if the child had ever had allergy, asthma, atopic eczema or allergic rhinitis diagnosed by a doctor. Regarding cow's milk allergy and wheat allergy, the parents were also asked to report whether the child still developed symptoms from the food in question.

Height $(\mathrm{cm})$ and weight $(\mathrm{kg})$ were measured and Body Mass Index (BMI) was calculated and divided into BMI-for-age weight status categories (underweight, normal, overweight, obese) according to the Centers for Disease Control and Prevention (CDC) percentiles, as described in the ISCOLE protocol [10].

\section{Vitamin D status}

Blood samples were collected from 171 children participating in the study between January $29^{\text {th }}$ and June $3^{\text {rd }}$ 2013. Serum 25(OH)D levels were assayed with an immunochemiluminescence assay, which measures 25(OH)D2 and 25(OH)D3 as the total 25(OH)D level (Roche Diagnostics). All blood measurements were analyzed in the laboratory of Helsinki University Hospital.

\section{Statistical analyses}

Due to the non-normal distribution of serum 25(OH)D levels, the variables were log-transformed. $\chi^{2}$ test, independent sample t-test and analysis of variance (ANOVA) were used for group comparisons. Associations were tested with Pearson or Spearman correlation and further analyzed 
with multivariate linear regression analysis adjusted with potential confounders. The confounders were selected based on the associations found in the present study, and in previous literature. All statistical analyses were performed using SPSS software (IBM SPSS Statistics for Windows, version 22).

\section{Results}

\section{Subject characteristics}

The characteristics of the study subjects and the prevalence of allergic diseases are presented in Table 1. Altogether 171 children participated in the study. The majority (94\%) of them were of Caucasian origin. Atopic eczema, allergic rhinitis and food allergy were the most frequently observed allergic diseases. The most commonly reported food allergy was cow's milk allergy. As many as $13 \%$ of the children had been diagnosed with cow's milk allergy sometime in earlier childhood, but the majority of them (81\%) did not get allergy symptoms from milk anymore. The other most frequently reported food allergies were to various raw fruits (11\%) and raw vegetables (9\%), egg (7\%) and peanut (5\%).

\section{Vitamin D intake}

In our study sample 108/171 (63\%) children reported drinking milk more than once a day. Eating fish according to recommendations (2-4 times a week) was reported by $46 / 171$ (27\%) of the subjects. Based on the frequency of consumption of milk products and fish and use of vitamin $D$ supplementation we calculated that roughly $57 \%$ of the daily vitamin D was obtained from the use of vitamin D supplement, $27 \%$ from milk products and $16 \%$ from fish. Daily or almost daily use of vitamin D supplement was observed in $60 \%$ of the children. Altogether $13 \%$ of the children reported no regular use of vitamin D containing supplements (Table 1 ).

In children with a history of cow's milk allergy the frequency of milk consumption was significantly lower compared to those without milk allergy. Only $7 / 21$ (33\%) of children with a previously diagnosed milk allergy reported drinking of milk more than once a day compared to 95/139 (68\%) of children with no such history ( $p=0.004)$. Correspondingly, $5 / 21(24 \%)$ of the milk allergic children did not drink milk at all in comparison to $5 / 139$ (4\%) of those without milk allergy $(p=0.004)$. The consumption of fish, cheese and other milk products was similar in both groups. The majority of children in both groups reported use of daily vitamin D supplementation ( $71 \%$ of those with a history of milk allergy and $58 \%$ of those without milk allergy, $p=0.720)$. The frequency of milk consumption did not differ in non-Caucasian and Caucasian children or according to gender ( $p=0.529, p=0.300$, respectively). 


\section{Vitamin D status}

Serum 25(OH)D levels were measured for 171 subjects between January and June. There was no seasonal variation in $25(\mathrm{OH}) \mathrm{D}$ levels. The mean serum $25(\mathrm{OH}) \mathrm{D}$ was $72.6 \pm 21.8 \mathrm{nmol} / \mathrm{L}$ (range 37 $147 \mathrm{nmol} / \mathrm{L})$. Vitamin D insufficiency $(<50 \mathrm{nmol} / \mathrm{L})$ was observed in $16 \%$ of the study population. None of the children had vitamin D deficiency (<30 nmol/L). In contrast, $39 \%$ of the children had serum 25(OH)D above $75 \mathrm{nmol} / \mathrm{L}$, only one child having 25(OH)D above $125 \mathrm{nmol} / \mathrm{L}$ (Fig. 2).

Girls had lower mean serum 25(OH)D compared with boys as did children of non-Caucasian origin compared with Caucasian children (Fig. 3). Boys spent significantly more time outdoors after school than girls (less than 1 hour: $12 \%$ of boys vs. $25 \%$ of girls; 4 hours: $15 \%$ of boys vs. $3 \%$ of girls, $\mathrm{p}=0.007)$. BMI showed negative correlation with serum 25(OH)D $(r=-0.161, \mathrm{p}=0.036)$ but the mean serum 25(OH)D did not differ between normal weight and overweight/obese children. Use of vitamin D supplement also correlated with serum 25(OH)D concentration $(r=0.262, \mathrm{p}=$ 0.001 ) and daily users of vitamin D supplement had significantly higher serum 25(OH)D than nonusers (Table 1).

The mean serum 25(OH)D did not differ in subjects with previously diagnosed allergic rhinitis, atopic eczema, wheat allergy, or asthma from those without these diagnoses (Table 1). However, in children with a history of cow's milk allergy, the mean serum 25(OH)D was significantly lower than in subjects without milk allergy (Table 1, Fig. 3).

\section{Major determinants of vitamin D status}

We evaluated the major determinants of vitamin $D$ status by multivariate linear regression analysis. Female gender, non-Caucasian, ethnic background, use of vitamin D supplements once a week or less (or never) and ever diagnosed cow's milk allergy were associated with lower vitamin D levels (Table 2).

$\mathrm{BMI}$, frequency of milk and fish consumption, season of sampling, parental education or time spent outdoors were not associated with vitamin D status.

\section{Discussion}

Our study among 171 10-year-olds shows that the vitamin D status of Finnish school-aged children is sufficient as most children had serum $25(\mathrm{OH}) \mathrm{D}$ above $50 \mathrm{nmol} / \mathrm{L}$. Lower vitamin D levels were associated with female gender, non-Finnish ethnicity, lack of vitamin D supplementation and a history of diagnosed cow's milk allergy. Our novel finding is that once diagnosed cow's milk allergy is reflected as lower vitamin D status at school-age.

In previous Nordic studies, the prevalence of vitamin D insufficiency was 71\% in 7-19 year-old Finnish children and $82 \%$ in 13-year-olds in Sweden $[13,14]$. In line with our findings, two recent Finnish studies showed increased 25(OH)D concentrations among 2-12 year-olds in 2003-2006 and 
6-8 year-olds in 2007-2009 after the fortification of milk products with vitamin D began in 2003 $[15,16]$. The study by Mäkinen et al. reported that the frequency of vitamin D insufficiency in Finnish children almost halved from $69.9 \%$ in $1998-2002$ to $37.3 \%$ in $2003-2006$. However, these studies were conducted before the increased fortification of fluid milk products and fat spreads in 2010, and before the 2011 recommendation of year-round use of vitamin D supplements to all children which have further improved vitamin D status.

To our knowledge, Finland is the only country worldwide where daily year-round vitamin D supplementation is recommended to children under 18 years of age [17]. Before the current recommendation, only $21 \%$ of six-year-old children used vitamin D supplements in Finland [18]. Our study is the first to indicate that after the changed vitamin D supplement recommendations, the use of supplements has increased in children. The results further indicate that the national recommendation for year-round use of vitamin $D$ supplements and the fortification of foods with vitamin D can be effective strategies to improve vitamin D status at population level. Nevertheless, we observed that $40 \%$ of the children in our study did not follow the supplementation recommendation. Similar to other studies, lack of vitamin D supplementation was associated with lower vitamin D levels [19]. This indicates that to ensure sufficient intake of vitamin D, special attention should be paid to this subgroup of children. The reason for not using vitamin $D$ supplementation can be related to e.g. parental education and other socioeconomic factors [20].

Cow's milk allergy is one of the most common food allergies affecting children [21]. The prevalence of self-reported lifetime milk allergy in Europe has been reported to be $6.0 \%$ [8]. In our study the prevalence of ever diagnosed milk allergy was as high as $13 \%$, however majority of the children had developed tolerance to milk. A limitation in this study is that the information on allergy diagnosis relied on parents' report. Milk hypersensitivity can also be caused by other factors such as lactose intolerance [22]. With the development of Finnish Current Care Guidelines on Food Allergy the diagnostic criteria for food allergy have changed [23]. Previously, positive reactions in specific immunoglobulin $E$ tests could lead to allergy diagnosis and children were put on elimination diets more easily whereas currently the diagnosis relies on elimination-provocation tests [24]. These reasons can also explain the high prevalence of milk allergy observed in this study.

Studies evaluating nutrient status of milk allergic children are limited but in a sample of 2-17 yearold US children cow's milk allergy associated with decreased growth and a trend toward lower vitamin D intake [25]. In our study milk allergy was associated with lower vitamin D status. Children diagnosed with milk allergy during childhood consumed less dairy products even though they no longer got allergic symptoms of milk. This suggests that restricted dietary habits established in early childhood may track into later life $[26,27]$. The majority of the children with milk allergy took vitamin $D$ supplements and frequency of fish consumption did not differ from the others but still their 25(OH)D levels were significantly lower. Our finding is similar to a recent study on 6-8 year-old Finnish children where the strongest determinant of vitamin D status was consumption of milk, and implies that vitamin D obtained from fortified dairy products is an effective means of improving vitamin D status [16]. Those children who do not regularly consume 
fortified milk products are at risk for lower vitamin D status and might benefit from higher vitamin D supplementation. However, the number of children with milk allergy included in our study was relatively small and limits our ability to draw strong conclusions. Furthermore, lower vitamin D status of milk allergic children may also be related to lower calcium intake, as calcium intake may affect 25(OH)D concentration [28]. Children on milk elimination diet face an increased risk of suboptimal intake of calcium [29].

Other factors associated with lower vitamin D status were female gender and non-Caucasian ethnicity. Dark skin pigmentation may be a risk factor for vitamin D deficiency [30]. Also, there may be genetic variation in vitamin $D$ binding protein levels in different ethnic groups. Female gender has been associated with lower vitamin D status also in other studies [19,31]. This could be due to the finding that girls spend less time outdoors than boys as seen also in our study [32]. However, in our cohort this is an unlikely explanation as most of the $25(\mathrm{OH}) \mathrm{D}$ measurements were performed during the season when sunlight exposure outdoors is limited. Biological differences may play a role. Girls have increased fat mass compared with boys and this may increase the proportion of vitamin D stored in the adipose tissue, with the expense of circulating levels of 25(OH)D [33].

We recognize some limitations in our study. This was a cross-sectional study with a relatively small number of subjects with measured 25(OH)D levels. Furthermore, we could not calculate accurate estimates for vitamin $D$ intake due to the used food frequency questionnaire which lacked information on consumed portion sizes and use of vitamin D fortified fat spreads. Further, no parathormone or vitamin D binding protein measurements were available.

In conclusion, the overall vitamin D status of Finnish school-aged children is sufficient after increased vitamin $D$ fortification of dairy products and initiation of the national guidelines of daily year-round vitamin D supplementation to all children. This indicates that public health strategies are an important means to increase vitamin D status in children. Lower vitamin D status was associated with female sex, non-Caucasian ethnicity and lack of regular vitamin $D$ supplementation. Vitamin D status was significantly lower in children with a history of cow's milk allergy indicating that restricting the diet of an allergic child may have long-term consequences on dietary habits and subsequently on vitamin D status in later childhood.

\section{Acknowledgments}

We are grateful to all the children and parents who participated in the study and to the research assistants for their role in data collection of the Finnish site of ISCOLE. 


\section{Disclosure statement}

This study is a sub-study of the International Study on Childhood Obesity, Lifestyle and the Environment (ISCOLE) which was funded by The Coca-Cola Company. The funder had no role in the design and conduct of the study; collection, management, analysis and interpretation of the data; and preparation, review or approval of the manuscript. The study was financially supported by Finska Läkaresällskapet, the Sigrid Jusélius Foundation, the Academy of Finland, the Foundation for Pediatric Research, and the Helsinki University Research Funds. The authors declare no conflicts of interest. 


\section{References}

[1] Holick MF: Vitamin D deficiency. N Engl J Med 2007;357:266-281.

[2] Chiu CY, Huang SY, Peng YC, Tsai MH, Hua MC, Yao TC, Yeh KW, Huang JL: Maternal vitamin D levels are inversely related to allergic sensitization and atopic diseases in early childhood. Pediatr Allergy Immunol 2015;26:337-343.

[3] Hypponen E, Laara E, Reunanen A, Jarvelin MR, Virtanen SM: Intake of vitamin D and risk of type 1 diabetes: a birth-cohort study. Lancet 2001;358:1500-1503.

[4] Munger KL, Levin LI, Hollis BW, Howard NS, Ascherio A: Serum 25-hydroxyvitamin D levels and risk of multiple sclerosis. JAMA 2006;296:2832-2838.

[5] Cashman KD, Dowling KG, Skrabakova Z, Gonzalez-Gross M, Valtuena J, De Henauw S, Moreno L, Damsgaard CT, Michaelsen KF, Molgaard C, Jorde R, Grimnes G, Moschonis G, Mavrogianni C, Manios Y, Thamm M, Mensink GB, Rabenberg M, Busch MA, Cox L, Meadows S, Goldberg G, Prentice A, Dekker JM, Nijpels G, Pilz S, Swart KM, van Schoor NM, Lips P, Eiriksdottir G, Gudnason V, Cotch MF, Koskinen S, Lamberg-Allardt C, Durazo-Arvizu RA, Sempos CT, Kiely M: Vitamin D deficiency in Europe: pandemic? Am J Clin Nutr 2016;103:1033-1044.

[6] Finnish National Nutrition Council: https://www.evira.fi/en/foodstuff/healthy-diet/nationalnutrition-council/announcements-and-action-plans/

[7] Thomsen SF: Epidemiology and natural history of atopic diseases. Eur Clin Respir J 2015;2:10.3402/ecrj.v2.24642. eCollection 2015.

[8] Nwaru BI, Hickstein L, Panesar SS, Roberts G, Muraro A, Sheikh A, EAACI Food Allergy and Anaphylaxis Guidelines Group: Prevalence of common food allergies in Europe: a systematic review and meta-analysis. Allergy 2014;69:992-1007.

[9] Sova C, Feuling MB, Baumler M, Gleason L, Tam JS, Zafra H, Goday PS: Systematic review of nutrient intake and growth in children with multiple IgE-mediated food allergies. Nutr Clin Pract 2013;28:669-675.

[10] Katzmarzyk PT, Barreira TV, Broyles ST, Champagne CM, Chaput JP, Fogelholm M, Hu G, Johnson WD, Kuriyan R, Kurpad A, Lambert EV, Maher C, Maia J, Matsudo V, Olds T, Onywera V, Sarmiento OL, Standage M, Tremblay MS, Tudor-Locke C, Zhao P, Church TS: The International Study of Childhood Obesity, Lifestyle and the Environment (ISCOLE): design and methods. BMC Public Health 2013;13:900-2458-13-900.

[11] Saloheimo T, Gonzáles SA, Erkkola M, Milauskas DM, Meisel JD, Champagne CM, Tudor-Locke C, Sarmiento O, Katzmarzyk PT, Fogelholm M: The reliability and validity of a short food frequency questionnaire among 9-11-year olds: a multinational study on three middle-income and highincome countries. Int J Ob Suppl 2015:S22-S28.

[12] Nwaru BI, Lumia M, Kaila M, Luukkainen P, Tapanainen H, Erkkola M, Ahonen S, Pekkanen J, Klaukka T, Veijola R, Simell O, Knip M, Virtanen SM: Validation of the Finnish ISAAC questionnaire on asthma against anti-asthmatic medication reimbursement database in 5-year-old children. Clin Respir J 2011;5:211-218.

[13] Pekkinen M, Viljakainen $H$, Saarnio E, Lamberg-Allardt C, Makitie O: Vitamin D is a major determinant of bone mineral density at school age. PLoS One 2012;7:e40090.

[14] Persson K, Ohlund I, Nordstrom L, Winberg A, Ronmark E, West CE: Vitamin D deficiency at the Arctic Circle - a study in food-allergic adolescents and controls. Acta Paediatr 2013;102:644649.

[15] Makinen M, Simell V, Mykkanen J, Ilonen J, Veijola R, Hyoty H, Knip M, Simell O, Toppari J, Hermann R: An increase in serum 25-hydroxyvitamin D concentrations preceded a plateau in type 1 diabetes incidence in Finnish children. J Clin Endocrinol Metab 2014;99:E2353-6. 
[16] Soininen S, Eloranta AM, Lindi V, Venalainen T, Zaproudina N, Mahonen A, Lakka TA: Determinants of serum 25-hydroxyvitamin $D$ concentration in Finnish children: the Physical Activity and Nutrition in Children (PANIC) study. Br J Nutr 2016;115:1080-1091.

[17] Spiro A, Buttriss JL: Vitamin D: An overview of vitamin D status and intake in Europe. Nutr Bull 2014;39:322-350.

[18] Kyttala P, Erkkola M, Kronberg-Kippila C, Tapanainen H, Veijola R, Simell O, Knip M, Virtanen SM: Food consumption and nutrient intake in Finnish 1-6-year-old children. Public Health Nutr 2010;13:947-956.

[19] Petersen RA, Damsgaard CT, Dalskov SM, Sorensen LB, Hjorth MF, Ritz C, Kjolbaek L, Andersen R, Tetens I, Krarup H, Astrup A, Michaelsen KF, Molgaard C: Vitamin D status and its determinants during autumn in children at northern latitudes: a cross-sectional analysis from the optimal wellbeing, development and health for Danish children through a healthy New Nordic Diet (OPUS) School Meal Study. Br J Nutr 2016;115:239-250.

[20] Rasanen M, Kronberg-Kippila C, Ahonen S, Uusitalo L, Kautiainen S, Erkkola M, Veijola R, Knip $M$, Kaila M, Virtanen SM: Intake of vitamin D by Finnish children aged 3 months to 3 years in relation to sociodemographic factors. Eur J Clin Nutr 2006;60:1317-1322.

[21] Sicherer SH, Sampson HA: Food allergy: Epidemiology, pathogenesis, diagnosis, and treatment. J Allergy Clin Immunol 2014;133:291-307; quiz 308.

[22] Winberg A, West CE, Strinnholm A, Nordstrom L, Hedman L, Ronmark E: Milk allergy is a minor cause of milk avoidance due to perceived hypersensitivity among schoolchildren in Northern Sweden. Acta Paediatr 2015;105:206-214.

[23] The Finnish Medical Society Duodecim: Finnish Current Care Guidelines on Food Allergy 2015. http://kaypahoito.fi/web/english/home

[24] Pelkonen AS, Kuitunen M, Dunder T, Reijonen T, Valovirta E, Mäkelä MJ: Allergy in children: practical recommendations of the Finnish Allergy Programme 2008-2018 for prevention, diagnosis, and treatment. Pediatric Allergy and Immunology 2012;23:103-116.

[25] Robbins KA, Wood RA, Keet CA: Milk allergy is associated with decreased growth in US children. J Allergy Clin Immunol 2014;134:1466-1468.e6.

[26] Mikkila V, Rasanen L, Raitakari OT, Pietinen P, Viikari J: Consistent dietary patterns identified from childhood to adulthood: the cardiovascular risk in Young Finns Study. Br J Nutr 2005;93:923931.

[27] Maslin K, Grundy J, Glasbey G, Dean T, Arshad SH, Grimshaw K, Oliver E, Roberts G, Venter C: Cows' milk exclusion diet during infancy: Is there a long-term effect on children's eating behaviour and food preferences? Pediatr Allergy Immunol 2016;27:141-146.

[28] Clements MR, Johnson L, Fraser DR: A new mechanism for induced vitamin D deficiency in calcium deprivation. Nature 1987;325:62-65.

[29] Tuokkola J, Luukkainen P, Nevalainen J, Ahonen S, Toppari J, Ilonen J, Veijola R, Knip M, Virtanen SM, Kaila M: Eliminating cows' milk, but not wheat, barley or rye, increases the risk of growth deceleration and nutritional inadequacies. Acta Paediatr 2017.

[30] Clemens TL, Henderson SL, Adams JS, Holick MF: Increased skin pigment reduces the capacity of skin to synthesise vitamin D3. Lancet 1982;319:74-76.

[31] Yao TC, Tu YL, Chang SW, Tsai HJ, Gu PW, Ning HC, Hua MC, Liao SL, Tsai MH, Chiu CY, Lai SH, Yeh KW, Huang JL, PATCH study group, Huang JL: Suboptimal vitamin D status in a populationbased study of Asian children: prevalence and relation to allergic diseases and atopy. PLoS One 2014;9:e99105. 
[32] Karaguzel G, Dilber B, Can G, Okten A, Deger O, Holick MF: Seasonal vitamin D status of healthy schoolchildren and predictors of low vitamin D status. J Pediatr Gastroenterol Nutr 2014;58:654-660.

[33] Ayyavoo A, Derraik JGB, Hofman PL, Biggs J, Cutfield WS: Metabolic, cardiovascular and anthropometric differences between prepubertal girls and boys. Clin Endocrinol (Oxf)

2014;81:238-243. 


\section{Figure legends}

Figure 1. Flow chart of data collection.

Figure 2. Distribution of serum 25(OH)D levels of the Finnish 10-year-olds ( $n=171)$.

Figure 3. Comparison of serum 25(OH)D levels according to gender, ethnicity and history of cow's milk allergy. There is difference in the serum 25(OH)D levels between boys and girls $(p<0.001)$, Caucasian and non-Caucasian children $(p=0.003)$ and children without and with a history of cow's milk allergy $(p=0.004)$. 
Table 1. Characteristics of the 171 schoolchildren in relation to serum 25(OH)D status.

\begin{tabular}{|c|c|c|c|c|c|}
\hline Characteristics & $\mathbf{n}$ & $\%$ & 25(OH)D nmol/L & SD & P-value \\
\hline \multicolumn{6}{|l|}{ Sex } \\
\hline Boy & 84 & 49 & 78.4 & 20.8 & $<0.001$ \\
\hline Girl & 87 & 51 & 67.1 & 21.4 & \\
\hline \multicolumn{6}{|l|}{ Ethnicity } \\
\hline Caucasian & 151 & 94 & 74.6 & 21.6 & 0.003 \\
\hline Non-Caucasian & 10 & 6 & 56.0 & 18.2 & \\
\hline \multicolumn{6}{|l|}{ BMI } \\
\hline Underweight/normal & 139 & 81 & 73.9 & 22.4 & 0.155 \\
\hline Overweight/obese & 32 & 19 & 67.2 & 18.0 & \\
\hline \multicolumn{6}{|l|}{ Parental education } \\
\hline High school or less & 43 & 27 & 72.2 & 22.9 & 0.828 \\
\hline College degree & 39 & 24 & 73.6 & 20.2 & \\
\hline Bachelor's/postgraduate degree & 79 & 49 & 74.0 & 22.3 & \\
\hline \multicolumn{6}{|l|}{ Vitamin D supplement use } \\
\hline No & 20 & 13 & 59.1 & 16.6 & 0.004 \\
\hline Once a week or less & 19 & 12 & 69.7 & 15.5 & \\
\hline 2-5 days a week & 24 & 15 & 75.0 & 17.8 & \\
\hline Yes, daily or almost daily & 95 & 60 & 77.1 & 23.4 & \\
\hline \multicolumn{6}{|l|}{ Season of blood sampling } \\
\hline Winter (January, February) & 43 & 25 & 70.1 & 23.3 & 0.537 \\
\hline Spring (March, April) & 75 & 44 & 73.0 & 21.3 & \\
\hline Summer (May, June) & 53 & 31 & 74.2 & 21.5 & \\
\hline \multicolumn{6}{|l|}{ Atopic eczema } \\
\hline Yes & 33 & 21 & 78.3 & 22.7 & 0.126 \\
\hline No & 127 & 79 & 72.3 & 21.5 & \\
\hline \multicolumn{6}{|l|}{ Allergic rhinitis } \\
\hline Yes & 32 & 20 & 70.9 & 18.1 & 0.585 \\
\hline No & 128 & 80 & 74.2 & 22.7 & \\
\hline \multicolumn{6}{|l|}{ Cow's milk allergy } \\
\hline Yes & 21 & 13 & 60.5 & 12.6 & 0.004 \\
\hline No & 139 & 87 & 75.5 & 22.3 & \\
\hline \multicolumn{6}{|l|}{ Wheat allergy } \\
\hline Yes & 5 & 3 & 65.0 & 9.8 & 0.484 \\
\hline No & 153 & 97 & 74.0 & 22.0 & \\
\hline \multicolumn{6}{|l|}{ Other food allergy } \\
\hline Yes & 30 & 19 & 74.0 & 20.9 & 0.775 \\
\hline No & 130 & 81 & 73.4 & 22.1 & \\
\hline \multicolumn{6}{|l|}{ Other allergy } \\
\hline Yes & 18 & 11 & 69.0 & 20.4 & 0.381 \\
\hline No & 142 & 89 & 74.1 & 22.0 & \\
\hline \multicolumn{6}{|l|}{ Asthma } \\
\hline Yes & 12 & 8 & 72.6 & 20.9 & 0.114 \\
\hline No & 148 & 92 & 84.8 & 30.4 & \\
\hline
\end{tabular}

25(OH)D, 25-hydroxyvitamin D; BMI, body mass index; SD, standard deviation Serum 25(OH)D levels were logarithmically transformed for analysis. Differences between means were tested by independent samples t-test or ANOVA (for more than two groups of cases). Missing values: ethnicity $6 \%$, parental education $6 \%$, vitamin D supplement use $8 \%$, wheat allergy $1 \%$. 
Table 2. Determinants of vitamin D status in Finnish 10-year-olds $(n=171)$; multivariate linear regression analyses for serum 25(OH)D levels.

Variable

Sex (girl vs. boy)

Ethnicity (non-Caucasian vs. Caucasian)

BMI $\left(\mathrm{kg} / \mathrm{m}^{2}\right)$

Cow's milk allergy (vs. no milk allergy)

Use of vitamin D supplement

(2-7 times a week vs. no or $\leq$ once a week)

\section{B coefficient}

\section{$P$}

$\begin{array}{ccc}-0.133 & -0.219,-0.048 & 0.002 \\ -0.196 & -0.382,-0.010 & 0.039 \\ -0.010 & -0.024,0.005 & 0.183 \\ -0.187 & -0.313,-0.061 & 0.004 \\ 0.140 & 0.039,0.241 & 0.007\end{array}$

$-0.133 \quad-0.219,-0.048 \quad 0.002$

$-0.196-0.382,-0.010 \quad 0.039$

$-0.010-0.024,0.005 \quad 0.183$

$0.140 \quad 0.039,0.241 \quad 0.007$

25(OH)D, 25-hydroxyvitamin D; BMI, body mass index; $\mathrm{Cl}$, confidence interval.

Serum 25(OH)D levels were logarithmically transformed for analysis. The model included all covariates presented in the Table. $\mathrm{R}^{2} 0.210, \mathrm{~F}=8.069$. 
Figure 1.

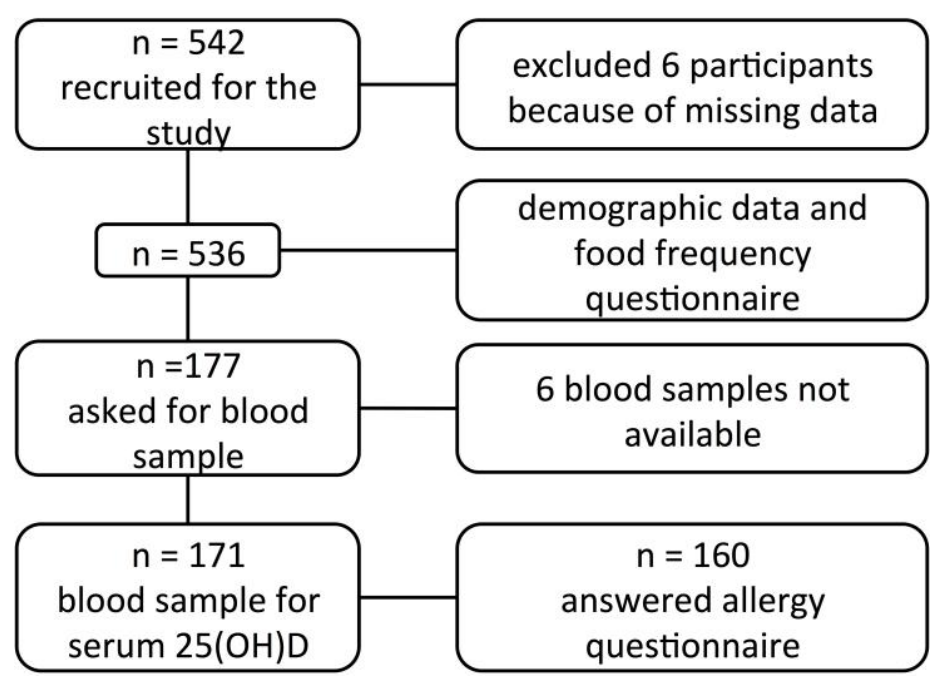


Figure 2.

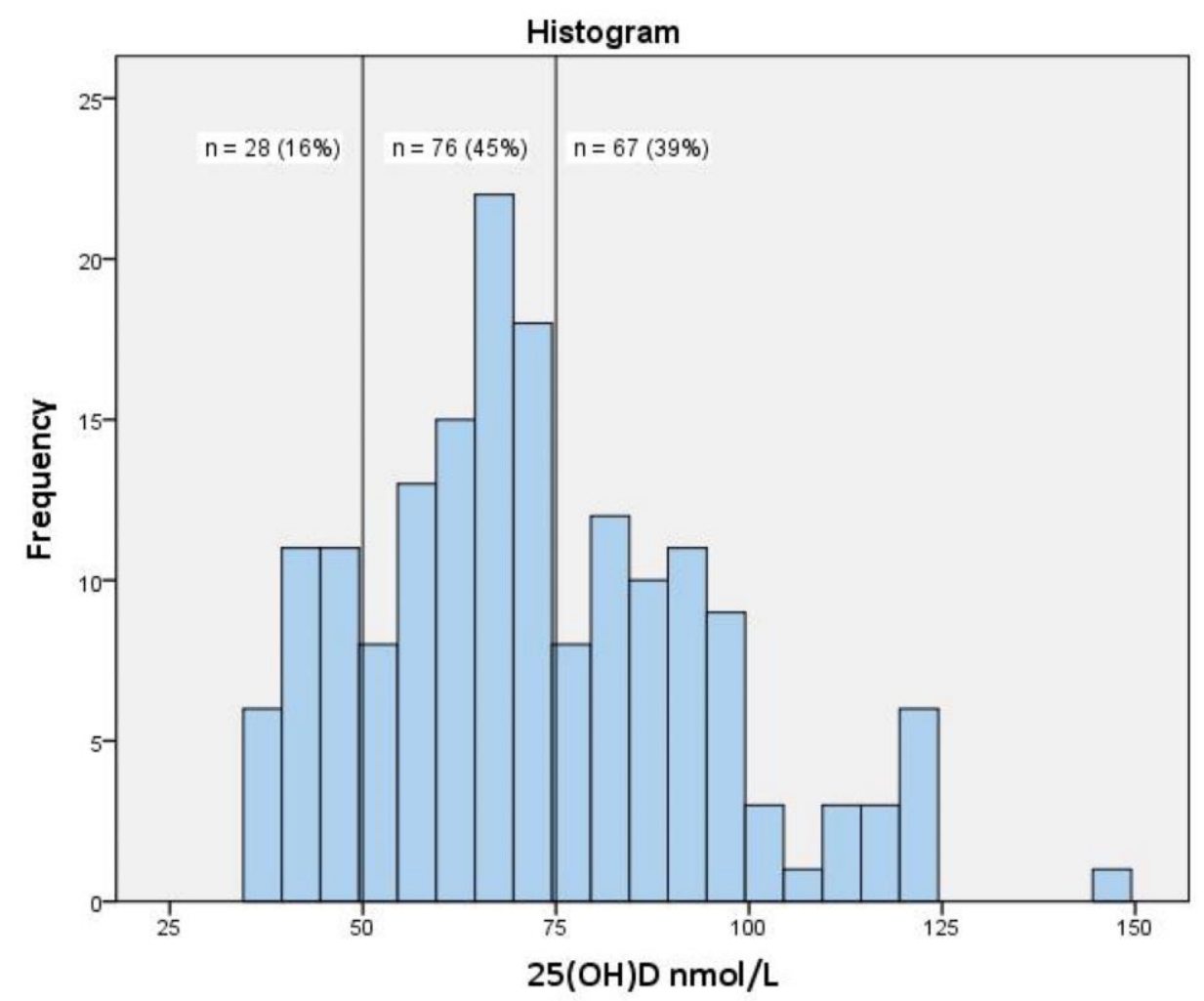


Figure 3.
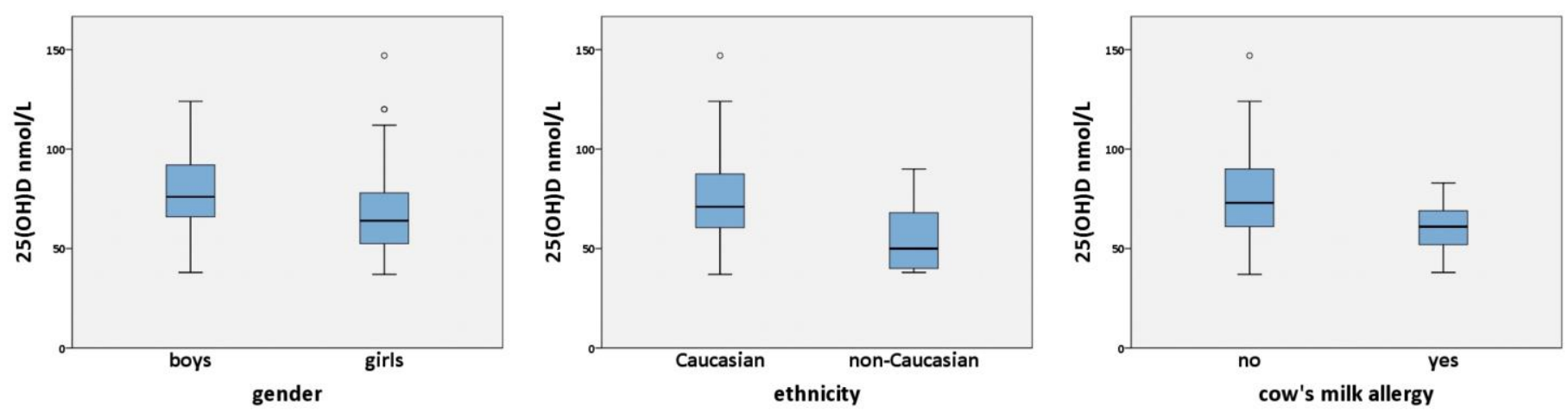